\title{
Membrane Interactions and Toxicity by Misfolded Protein Oligomers
}

\author{
Mario Gonzalez-Garcia ${ }^{1}$, Giuliana Fusco ${ }^{2}$ and Alfonso De Simone ${ }^{1,3 *}$ \\ ' Department of Life Sciences, Imperial College London, South Kensington, United Kingdom, ${ }^{2}$ Department of Chemistry, \\ Centre for Misfolding Diseases, University of Cambridge, Cambridge, United Kingdom, ${ }^{3}$ Department of Pharmacy, University \\ of Naples Federico II, Naples, Italy
}

The conversion of otherwise soluble proteins into insoluble amyloid aggregates is associated with a range of neurodegenerative disorders, including Alzheimer's and Parkinson's diseases, as well as non-neuropathic conditions such as type II diabetes and systemic amyloidoses. It is increasingly evident that the most pernicious species among those forming during protein aggregation are small prefibrillar oligomers. In this review, we describe the recent progress in the characterization of the cellular and molecular interactions by toxic misfolded protein oligomers. A fundamental interaction by these aggregates involves biological membranes, resulting in two major model mechanisms at the onset of the cellular toxicity. These include the membrane disruption model, resulting in calcium imbalance, mitochondrial dysfunction and intracellular reactive

OPEN ACCESS

Edited by: Neville Vassallo,

University of Malta, Malta

Reviewed by:

John H. Viles,

Queen Mary University of London,

United Kingdom

Carmelo La Rosa,

University of Catania, Italy

*Correspondence:

Alfonso De Simone

adesimon@imperial.ac.uk

Specialty section:

This article was submitted to

Molecular Medicine,

a section of the journal

Frontiers in Cell and Developmental

Biology

Received: 16 December 2020

Accepted: 08 February 2021

Published: 11 March 2021

Citation:

Gonzalez-Garcia M, Fusco G and

De Simone A (2021) Membrane

Interactions and Toxicity by Misfolded

Protein Oligomers.

Front. Cell Dev. Biol. 9:642623.

doi: 10.3389/fcell.2021.642623 oxygen species, and the direct interaction with membrane proteins, leading to the alteration of their native function. A key challenge remains in the characterization of transient interactions involving heterogeneous protein aggregates. Solving this task is crucial in the quest of identifying suitable therapeutic approaches to suppress the cellular toxicity in protein misfolding diseases.

\section{Keywords: protein misfolding, membrane interaction, receptor binding, amyloid fibrils, cellular toxicity}

\section{INTRODUCTION}

The misfolding and aggregation of otherwise functional proteins is linked with a number of neurodegenerative disorders such as Alzheimer's disease (AD) and Parkinson's disease (PD), as well as non-neuropathic conditions such as type II diabetes (T2D) and systemic amyloidoses. The protein fibrils forming in association with these pathologies share common properties such as a core rich in $\beta$-sheet structure adopting a characteristic cross- $\beta$ topology, the resistance to degradation and significant mechanical properties with tensile strength that is similar to steel. The precursor proteins involved in protein misfolding diseases (PMDs), however, are considerably different in their native states and range from disordered proteins (e.g., amyloid-beta - $\mathrm{A} \beta$ - in $\mathrm{AD}$, $\alpha$-synuclein $-\alpha$ Syn - in PD, the prion protein in prion disease) to structured monomers (e.g., beta2 microglobulin $-\beta 2 \mathrm{~m}-$ in $\beta 2 \mathrm{~m}$-amyloidosis) or globular oligomers (the transthyretin - TTR tetramer in TTR-amyloidosis). The structural similarity between the mature amyloid aggregates has suggested the existence of some generic mechanism of toxicity. One of the recursive mechanisms includes the impairment of clearance control processes that suppress protein aggregation and toxicity in the cell, which is likely coupled with the higher prevalence of these conditions in aging populations. A detailed understanding of the molecular origins of PMDs is, however, missing, including the balance between loss of function of native proteins or gain in toxicity by aberrant aggregates. 
In this review, we summarize the state of the art in the study of the mechanisms of toxicity associated with aberrant protein aggregation, with a specific focus on the interaction between protein oligomers and biological membranes, a central step at the onset and development of PMDs.

\section{TOXICITY OF PROTEIN OLIGOMERS}

It is now recognized that the most toxic species in the etiology of PMDs are the small and diffusible prefibrillar oligomers forming during protein aggregation or released by mature fibrils (Hartl, 2017). Protein oligomers have been shown to induce higher levels of cellular toxicity than mature fibrils. This has been consistently observed in many protein systems including $A \beta$ (Walsh et al., 2002) and tau (Ward Sarah et al., 2012) in AD, $\alpha$ Syn (Winner et al., 2011) in PD and human islet amyloid polypeptide (IAPP) in type II diabetes (Abedini et al., 2016; Scollo and La Rosa, 2020). Compared to mature fibrils, protein oligomers have specific molecular structural characteristics that enhance their ability to induce neurotoxicity, including small size (Mannini et al., 2014), exposure of hydrophobic surfaces (Vivoli Vega et al., 2019) and unsaturated edge-strands (De Simone et al., 2008). The transient and heterogeneous nature of these species, however, makes it elusive to study their properties in vitro or in vivo. Recent investigations have been successful in identifying some of the key properties at the origin of the cellular toxicity by misfolded protein oligomers, including the disruption of the mitochondrial function (Westermark et al., 2011; Ghio et al., 2019), the induction of increased levels of basal calcium (Angelova et al., 2016), the generation of metal dyshomeostasis (Angelova et al., 2016) and stimulation of reactive oxygen species (Cheignon et al., 2018). A central role in most of these mechanisms of toxicity is the interaction between misfolded protein oligomers and biological membranes, including plasma and mitochondrial membranes (Figure 1), which will be overviewed here with respect to two major models, namely the membrane disruption and receptor-mediated interaction.

\section{DISRUPTION OF BIOLOGICAL MEMBRANES BY TOXIC PROTEIN OLIGOMERS}

Oligomers in PMDs have been shown to disrupt a variety of cellular processes, including alterations of the calcium signaling (Quist et al., 2005; Kim et al., 2018) due to the disruption of the plasma membrane (Lin et al., 2001; Angelova et al., 2016). Several molecular mechanisms have been identified for the plasma membrane permeabilization by various types of misfolded protein oligomers (Figure 2). In the case of $\alpha$ Syn, oligomers are believed to disrupt the neuronal membrane by binding the lipid bilayer via the N-terminal region of the protein and by inserting their core into its hydrophobic interior (Fusco et al., 2017). This mechanism favors fluxes through the neuronal membrane of small ions and larger molecules such as the calcein dye (Cascella et al., 2019). By directly targeting the lipophilic region of the oligomers using antibodies, the toxicity of $\alpha$ Syn aggregates is suppressed, as shown in vitro and C. elegans (Cascella et al., 2019). The permeabilization of the plasma membrane upon interaction with protein oligomers has also been shown by electrophysiology studies of membrane conductance (Feng et al., 2010). These observations are consistent with the formation of pores of different dimensions in the membrane upon treatment with oligomers (Wong Su et al., 2018), as observed using atomic force microscopy (Chaudhary et al., 2016; Oropesa-Nuñez et al., 2016; Bode et al., 2019). The ability to generate these pores has been associated to the exposure of hydrophobic regions (Vivoli Vega et al., 2019) and the size of the protein oligomers (Mannini et al., 2014; Chiti and Dobson, 2017).

Another model is based on evidence supporting the formation of ion channels by protein oligomers at the origin of the pathophysiology for amyloid diseases. A $\beta 42$ has been shown to form discrete pore structures ranging between 1.7 and $2.4 \mathrm{~nm}$ in diameter (Bode et al., 2017). The architecture and dimensions of these pores resemble annular $A \beta$ oligomers that had previously been shown to form tetrameric and hexameric channel-like structures by atomic force microscopy (Lin et al., 2001; Quist et al., 2005; Jang et al., 2010), which were also shown to generate discrete current bursts. Similar channel-like structures have been reported for $\alpha$ Syn (Lashuel et al., 2002; Kayed et al., 2009; Chen et al., 2015) having ion channel-like activity (Kim et al., 2009; Tosatto et al., 2012). These findings suggest an additional common mechanism of alteration of ion homeostasis in the pathogenesis of PMDs.

The membrane interaction by misfolded protein oligomers is also strongly influenced by the lipid composition, which is a modulator of the downstream cellular toxicity. An increase in the content of gangliosides and cholesterol in the cellular membrane enhances the toxicity of misfolded oligomers of the HypF-N protein model system in vitro (Evangelisti et al., 2012). This is consistent with evidence of a correlation between age-related alterations of the lipid homeostasis and neurodegenerative diseases, as well as with altered fractions of gangliosides in brains of Alzheimer's patients (Yamamoto et al., 2008), including membrane fractions from the frontal cortex and the temporal cortex (Molander-Melin et al., 2005) as well as in lipid rafts (Liu et al., 2015a).

Neurodegenerative conditions also feature lipid peroxidation due to oxidative stress, which has been shown to enhance protein misfolding and aggregation as well as to promote membrane permeability (Liu et al., 2008; Choi and Gandhi, 2018; Michalska and León, 2020). This generates a positive feedback mechanism in which the peroxidation of the membrane triggers more vigorous protein aggregation, as shown for A $\beta$ (Pilkington et al., 2019) and $\alpha$ Syn (Angelova et al., 2020a), which in turn generates additional oligomers, thereby enhancing the oxidative stress and lipid peroxidation. Products of lipid peroxidation have been found in brains of both $\mathrm{PD}$ and $\mathrm{AD}$ patients, as well as in animal models of such diseases (Joshi et al., 2006; Picklo and Montine, 2007; Dalfó and Ferrer, 2008; Padurariu et al., 2010). Peroxidation leads to defects in the packing of the phospholipids and weakens cellular membranes, making them more vulnerable to pore formation induced by protein aggregates. Oxidative stress 


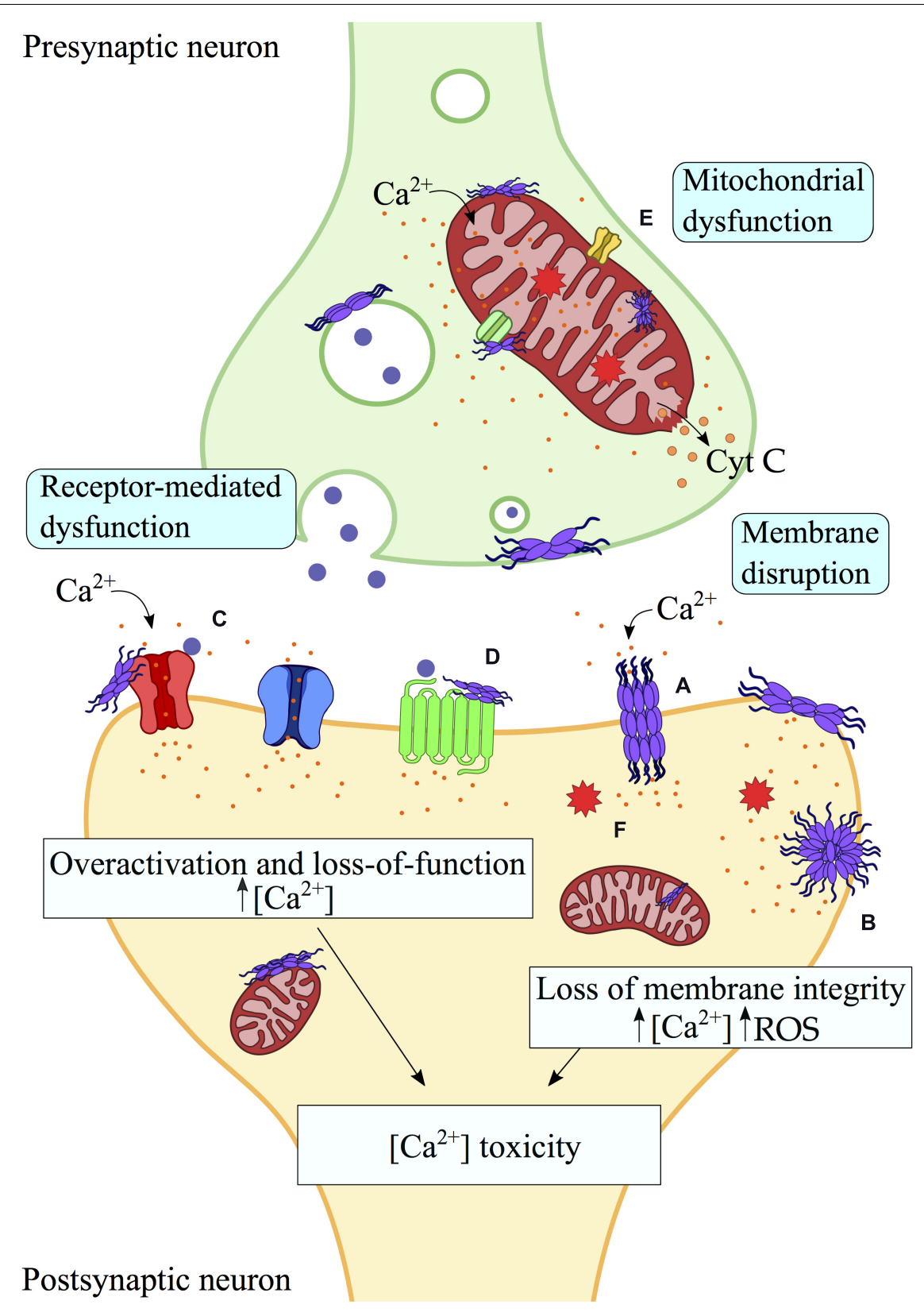

FIGURE 1 | Aberrant interactions between misfolded protein aggregates and biological membranes. Toxic protein oligomers can bind strongly biological membranes, including plasma and mitochondrial membranes, as well as membrane proteins. Perturbation and pore formation (A) of the lipid bilayer by misfolded protein aggregates may generate membrane disruption and ultimately its permeabilization (B), leading to aberrant processes such as mitochondrial dysfunction, intracellular ROS and release of cytochrome c. In addition, interactions of misfolded protein aggregates with membrane receptors (C,D) and mitochondrial receptors (E) result in loss of function (e.g., VDACs, $\alpha 3-N K A$ ) or overactivation (e.g., mGluRs, NMDARs), with consequent alteration of the cellular viability, including calcium gradient imbalance and cellular and organelle dysfunction. Indeed, most of the interactions of misfolded protein aggregates with cellular membranes and membrane proteins have a common downstream effect on the $\mathrm{Ca}^{2+}$-dependent toxicity. In this scheme, interactions and processes by protein oligomers at the surface of biological membranes are shown. (A) Pore formation. (B) Membrane permeabilization. (C) Interaction with lonotropic/metabotropic glutamate receptors.

(D) Interaction with plasma membrane receptors (e.g., a7 nAChR, a3-NKA, etc.). (E) Mitochondrial receptors interactions (VDACs, mPTP, etc.). (F) Intracellular ROS production. Protein aggregates are schematically shown in purple, $\mathrm{Ca}^{2}+$ ions in orange and neurotransmitter molecules in blue.

also alters the chemical integrity of proteins, which is also a way to promote aggregation of amyloidogenic proteins (Angelova et al., 2020b), leading to a feed-forward loop where aberrant interactions with membranes are intensified.
It has also been proposed that complexes between misfolded proteins and free lipids in solution would be at the origin of membrane disruption in PMDs (lipid-chaperone hypothesis). The model suggests that pre-binding to lipids would favor the 


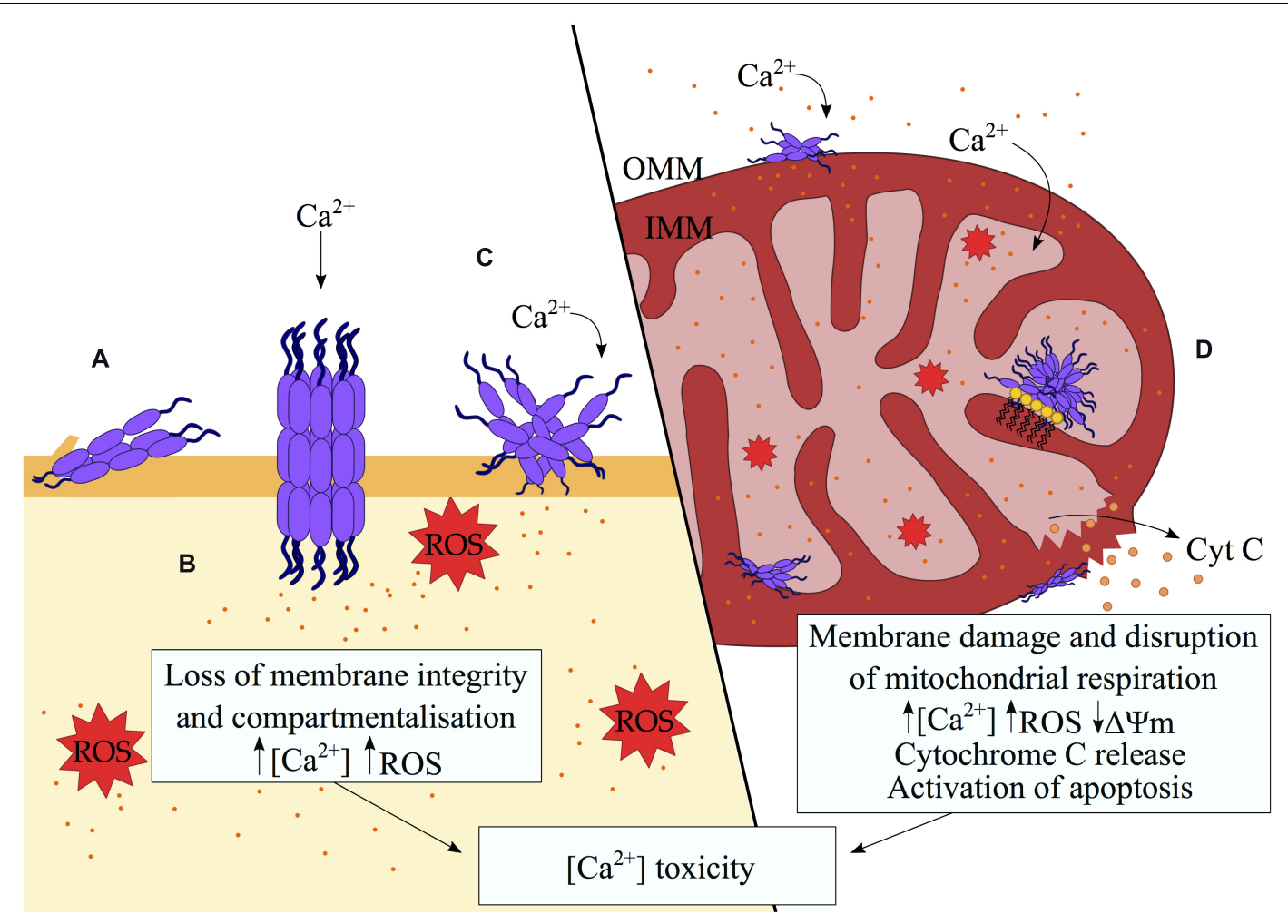

FIGURE 2 | Disruption of biological membranes by misfolded protein oligomers. A variety of mechanisms of membrane disruption by misfolded protein oligomers were proposed including (A) partial insertion of the oligomers into the hydrophobic region of the membrane, (B) pore formation, (C) membrane thinning and redistribution of lipids through a detergent-like mechanism (Sciacca et al., 2018). The consequent loss of membrane integrity results in aberrant Ca ${ }^{2+}$ influx, the generation of ROS and the alteration of signaling pathways, ultimately inducing cell death in a Ca ${ }^{2+}$-dependent manner. (D) In the mitochondria, preferential binding to cardiolipin (depicted as yellow lipids) by misfolded protein oligomers promotes aberrant protein-membrane interactions. Defects in the mitochondrial membranes lead to ionic gradient imbalances, which in turn interrupt the electron transport chain and compromise the process of mitochondrial respiration. A defective mitochondrial electron transport chain, in association with elevated $\mathrm{Ca}^{2+}$ influx result in an increase in intracellular ROS. The loss of mitochondrial membrane potential signals the release of cytochrome c.

insertion of oligomers into the membrane in a chaperonelike mechanism (La Rosa et al., 2016; Scollo et al., 2018; Sciacca et al., 2020).

\section{MITOCHONDRIAL MEMBRANE DISRUPTION}

Oxidative phosphorylation in the mitochondria is responsible for most of the energy required for normal cellular function, a process that is particularly relevant for neuronal cells where a significant energetic consumption is required for synaptic transmission (Attwell and Laughlin, 2001). The mitochondrial dysfunction has been associated to most PMDs (Cenini et al., 2019), and evidence exists for a role of misfolded protein oligomers in the impairment of the mitochondrial function. Post-mortem brains of $\mathrm{PD}$ and $\mathrm{AD}$ patients indeed revealed the co-localization of aggregates of $\mathrm{A} \beta, \alpha$ Syn and tau with mitochondrial membranes (Hsu et al., 2000) and mitochondrialassociated membranes (Guardia-Laguarta et al., 2014). In vitro and animal studies have shown that prefibrillar oligomers induce neuronal death following mitochondrial membrane damage and mitochondrial dysfunction (Lashuel, 2005; Glabe, 2006; Cenini et al., 2019; Farrugia et al., 2020; Figure 2). Misfolded protein oligomers from tau, A $\beta$, IAPP, and $\alpha$ Syn have generally high affinity for the lipid composition of mitochondria, and particularly for their cardiolipin component (Camilleri et al., 2013, 2020; Kegulian et al., 2015; Ghio et al., 2019). Cardiolipin is a fundamental phospholipid that is exclusively found in mitochondrial membranes, where it plays a crucial role in many biochemical processes, including respiration and signaling. The characteristic structure of cardiolipin, which is formed by two phosphatidyl residues and four acyl chains joined by a glycerol bridge, has a profound effect on the curvature and packing of mitochondrial membranes (Horvath and Daum, 2013) and promotes the binding of protein oligomers (Elías-Wolff et al., 2019).

In the pathophysiology of $\mathrm{PD}$, mitochondrial dysfunction is a strong element inducing neuronal impairment. Transmission electron microscopy analysis of dopaminergic neurons overexpressing wild-type $\alpha$ Syn demonstrated abnormal mitochondrial morphologies, including fragmentation and malformed cristae (Ganjam et al., 2019). Indeed, several mutations in genes responsible for mitochondrial and reactive 
oxygen species (ROS) homeostasis (PINK1, PINK2 (Parkin), LRRK2, and DJ-1) have been shown to lead to PD (Bonifati et al., 2002; Valente et al., 2004; Gilks et al., 2005; Nichols et al., 2005). In vitro incubation of $\alpha$ Syn with isolated mitochondria (Ghio et al., 2019) results in the formation of membrane pores in a cardiolipin-dependent manner. Amounting evidence has demonstrated the accumulation of $\alpha$ Syn specifically on the internal mitochondrial membrane (IMM) (Devi et al., 2008), which is rich in cardiolipin (20\% of total lipids) compared to the outer mitochondrial membrane [OMM (5\% of lipid content)] (Klingenberg, 2009; Horvath and Daum, 2013; Pariary et al., 2019). Prefibrillar $\alpha$ Syn oligomers have been shown to trigger an unregulated influx of $\mathrm{Ca}^{2+}$, leading to mitochondrial calcium overload in isolated mitochondria and in dopaminergic neuronal models (Luth et al., 2014; Angelova et al., 2016). This induced the opening of the mitochondrial permeability transition pore (mPTP) (Luth et al., 2014), triggering the depolarization of the mitochondria (Sherer et al., 2002; Banerjee et al., 2010; Nakamura, 2013) and the release of cytochrome c (Hsu et al., 2000; Devi et al., 2008; Luth et al., 2014), leading in turn to the activation of cytoplasmic caspases signaling for a downstream apoptotic response (Ganjam et al., 2019).

Consistent with these findings, tau oligomers, but not monomers or fibrils, were able to disrupt model mitochondrial membranes in a cardiolipin-dependent manner (Camilleri et al., 2020), whereas the ability of tau to inhibit calcium efflux from the mitochondria was shown to induce mitochondrial depolarization in cortical neurons with consequent calcium-induced caspase 3 activation (Britti et al., 2020). Emerging evidence reported the perturbation of the mitochondrial membranes by $\mathrm{A} \beta 42$ oligomers (Glabe, 2006; Reddy, 2009; Camilleri et al., 2013; Oren et al., 2020) resulting in the impairment of calcium homeostasis, the reduction in the activity of respiratory chain complex I and IV (Mutisya et al., 1994; Casley et al., 2002; Rhein et al., 2009), and the induction of apoptotic pathways (Resende et al., 2008; Umeda et al., 2011; Bhat et al., 2015).

In the context of amyotrophic lateral sclerosis (ALS), aggregates of superoxide dismutase 1 (SOD1) have been associated with widespread mitochondrial dysfunction and mitochondrial membrane perturbation, as mitochondrial defects have been observed in tissues from ALS patients (Hirano et al., 1984). SOD1 aggregates were observed to bind the cytoplasmic leaflet of the OMM (Deng et al., 2006; Lin and Beal, 2006) and localize with mitochondria in a tissuedependent manner (Vande Velde et al., 2008). Mitochondrial dysfunction as a result of membrane integrity defects caused by misfolded SOD1 has been reported in vitro in neuronal cells (Carrì et al., 1997; Menzies et al., 2002) and in vivo in mutant SOD1 transgenic rodent models (Higgins et al., 2002; Mattiazzi et al., 2002), as well as in ALS patients (Swerdlow et al., 1998; Wiedemann et al., 2002). Moreover, in vitro incubation of SOD1 oligomers and fibrils was observed to lead to the permeabilization of the membranes of isolated rat brain mitochondria (Oladzad Abbasabadi et al., 2013).

Perturbation of mitochondrial membranes is also found in non-neuropathic amyloidoses, including lysozyme systemic amyloidosis, T2D and type I diabetes (T1D) (Gurlo et al., 2010;
Westermark et al., 2011, 2017). IAPP aggregates, associated with the pathology of $\mathrm{T} 2 \mathrm{D}$, have been shown to perturb mitochondrial membranes and accumulate at mitochondrial cristae (Kegulian et al., 2015). Membrane-associated IAPP oligomers have also been shown to have a general ability to permeate the plasma membrane through the formation of small and large pores, of which only the latter were considered cytotoxic (Pannuzzo et al., 2013; Birol et al., 2018). Indeed, mitochondrial membrane depolarization downstream of membrane damage (Birol et al., 2018) has been associated with cellular dysfunction and apoptosis in T2D (Gurlo et al., 2010). Whether disruption of the mitochondrial membranes is the initial step, or a major amplifier in the process of cell death leading to loss of $\beta$-cells in the pancreas during the development of diabetes, remains unclear. Similarly, perturbation of mitochondrial membranes by prefibrillar oligomers but not monomers or fibrils of hen egg white lysozyme has been observed in vitro using isolated rat brain mitochondria (Meratan et al., 2011; Meratan and Nemat-Gorgani, 2012), with membrane defects causing the release of mitochondrial enzymes and cytochrome c (Meratan et al., 2011).

\section{RECEPTOR-MEDIATED TOXICITY BY PROTEIN OLIGOMERS}

In addition to promoting loss of membrane integrity, misfolded protein aggregates have been proposed to induce toxicity via direct interaction with membrane proteins (Figure 3). The "receptor-mediated model" of toxicity of misfolded protein oligomers involves a plethora of membrane proteins and results in the transduction of deleterious signals and ultimately cellular toxicity.

The glutamate receptor family - metabotropic glutamate receptors (mGluR), $N$-methyl-D-aspartate receptors (NMDAR) and AMPA receptors (AMPAR) - has emerged as a key target for the intracellular transduction of toxic signals by misfolded proteins. The metabotropic glutamate mGluR5 receptors are amongst the major receptors for $\mathrm{A} \beta$ aggregates, as their colocalization has been repeatedly reported (Casley et al., 2009; Lim et al., 2013; Shrivastava et al., 2013). Indeed, knockout of mGluR5s results in a reduction in neurodegeneration induced by $A \beta$ oligomers (Hamilton et al., 2014). Trapping of mGluR5s receptors by $\mathrm{A} \beta$ aggregates results in the increased localization of the glutamate receptors at excitatory synapses and dendritic spines, generating a constitutively active signaling complex that leads to an increased mGluR5s-dependent intracellular $\mathrm{Ca}^{2+}$ signal (Renner et al., 2010). In the presence of $\mathrm{A} \beta$ oligomers, mGlu5Rs mediate the excessive release of $\mathrm{Ca}^{2+}$ from the endoplasmic reticulum (ER) in neurons and consequently lead to cellular toxicity (Renner et al., 2010; Um et al., 2013). Indeed, upregulation of mGlu5Rs has been observed in brains of PD patients, suggesting a putative role for mGlu5Rs receptors in protein oligomer pathology in PD (SanchezPernaute et al., 2008; Price et al., 2010; Morin et al., 2013). In general, an increased expression of mGlu5Rs seen in $\mathrm{AD}$, $\mathrm{PD}$ and other neurodegenerative diseases results in an elevated 


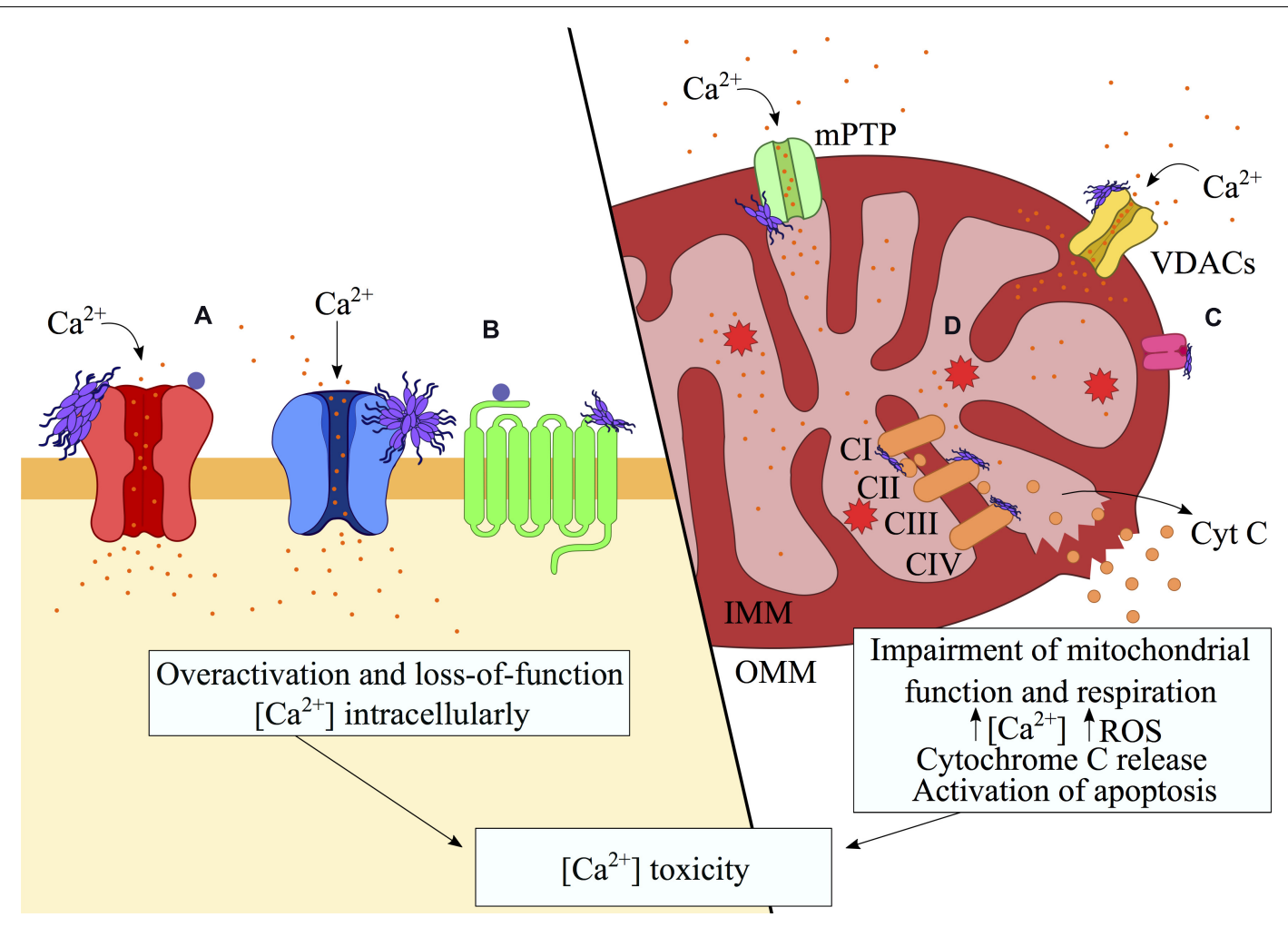

FIGURE 3 | Aberrant interactions of misfolded protein oligomers with membrane receptors. Misfolded protein oligomers are able to bind a variety of proteins on the plasma and mitochondrial membranes, resulting in the alteration of their functions. These interactions may result in overactivation and hence gain-of-function (e.g., mGluR5s or NMDARs) whereas internalization (e.g., AMPARs, $\alpha 7$ AChR) and clustering of transporters (e.g., $\alpha 3-N K A)$ may lead to loss-of-function. The binding to the receptors has been shown to alter the ionic gradients and generate an excess of intracellular and mitochondrial $\mathrm{Ca}^{2+}$. The resulting opening of the mPTP causes the depolarization of the mitochondria, which triggers the release of cytochrome $\mathrm{c}$ and consequent signaling for apoptosis. Disruption of the electron transport chain by direct binding of oligomers to the respiratory complexes exacerbates the calcium-mediated toxicity through the unregulated generation of ROS. In this schematic figure, interactions with (A) ionotropic/metabotropic glutamate receptors, (B) nicotinic receptors (e.g., NKA transporter) and (C) mitochondrial receptors (e.g.,

TOM20), are shown in association with (D) the resulting ROS generation.

availability of mGlu5Rs at the synapses, which is likely to be responsible for the observed rise in intracellular $\mathrm{Ca}^{2+}$ and consequent calpain activation, ER stress and cell death (Mattson, 2007).

Oligomeric A $\beta$ may also contribute to neurotoxicity through the overactivation of the ionotropic glutamate receptor NMDA, which is involved in synaptic plasticity stimulation, memory, learning and the assembly of neuronal connections ( $\mathrm{Li}$ and Tsien, 2009). By interfering with the function of NMDA receptors, $\mathrm{A} \beta$ oligomers trigger an abnormal influx of $\mathrm{Ca}^{2+}$ into neurons, which can lead to excitotoxicity (Alberdi et al., 2010; Liang et al., 2017). A $\beta$ oligomers also stimulate the internalization of AMPA receptors in a calcineurin-dependent manner (Hsieh et al., 2006), resulting in receptor depletion from the postsynaptic surface, as well as trafficking of AMPAR to the membrane upon synaptic potentiation (Rui et al., 2010). Additionally, the potential coupling of NMDA receptors with other synaptic receptors such as $\alpha 3$-NKA and mGlu5Rs, could compromise the physiological function of NMDA, thereby impairing long-term potentiation (LTP) (Hu et al., 2014).

The association between $A \beta$ and the cellular prion protein $\left(\operatorname{PrP}^{C}\right)$ has recently attracted a large attention. $\operatorname{PrP}^{C}$ has putatively high affinity for $A \beta$ oligomers and has been suggested to induce neurotoxic processes through the mediation of $A \beta$ toxicity (Laurén et al., 2009; Salazar et al., 2017; Brody and Strittmatter, 2018; Purro et al., 2018; Zhang et al., 2019), leading to the impairment of synaptic plasticity and defects in LTP in AD (Freir et al., 2011). Acting as an extracellular platform with the ability to coordinate multiprotein interactions, $\operatorname{PrP}^{C}$ has been proposed to mediate downstream signaling intracellularly from the cell surface upon $A \beta$ binding (e.g., mGluR5, $\alpha 7$ AChR) (Um et al., 2013; Haas et al., 2014, 2016; Hu et al., 2014; Zhang et al., 2019). Specifically, the interaction between $A \beta$ and $\operatorname{PrP}^{C}$ has been implicated in dendritic spine loss through the activation of the Fyn kinase, and the consequent phosphorylation of the NR2B subunit of the NMDA receptor (Um et al., 2012; Brody and Strittmatter, 2018). Downstream of Fyn activation is the tyrosine kinase Pyk, which has been shown to phosphorylate tau (Li and Götz, 2018), a step associated with AD (Iqbal et al., 2010). Furthermore, the $A \beta / \operatorname{PrP}^{C}$ interaction can recruit the lowdensity lipoprotein receptor-related protein-1 (LRP1) to facilitate the cell internalization of $A \beta$ aggregates (Rushworth et al., 2013). LRP1 has also been implicated in tau endocytosis and spread (Rauch et al., 2020), and may therefore potentially control the 
internalization of both toxic forms of tau and $\mathrm{A} \beta$ in $\mathrm{AD}$. More generally, $\operatorname{PrP}^{C}$ has been described as a mediator of the toxicity of a number of misfolded proteins involved in neurodegeneration. $\alpha$ Syn and tau have been shown to bind immobilized PrP, on mouse cortical neurons and in vivo (Ferreira et al., 2017; Corbett et al., 2020). In addition, the interaction between $\alpha$ Syn and $\operatorname{PrP}^{C}$ appears to induce aberrant $\mathrm{Ca}^{2+}$ levels and synaptic deficits in an mGluR5-mediated manner involving activation of the NMDA receptor (Ferreira et al., 2017).

In addition to a gain of function of membrane receptors, the interaction with protein aggregates may also result in loss of function, as in the case of the $\alpha 3-\mathrm{Na}^{+} / \mathrm{K}^{+}$ATPase $(\alpha 3$ NKA) sodium pump upon binding with $\mathrm{A} \beta$ and $\alpha$ Syn aggregates (Ohnishi et al., 2015; Shrivastava et al., 2015). The activity of the NKA transporter is strongly associated with the brain energy consumption, leading to the possibility that its impairment may be involved in an energy crisis in the brain (Shrivastava et al., 2017). A $\beta$ oligomers have been shown to impair the NKA catalytic activity, whilst $\alpha$ Syn has been shown to compromise the ability of this transporter to readily export sodium ions as a result of co-clustering around synapses. Additionally, a recent study demonstrated the ability of mutant SOD1 to interact also with a3-NKA in ALS (Ruegsegger et al., 2016).

Misfolded protein oligomers have also been observed to interact with mitochondrial membrane proteins. Voltagedependent anion channels (VDACs) in the mitochondrial outer membrane have been reported to play a role in the toxicity associated with protein misfolding. It has been proposed that VDAC may allow the entry of $\alpha$ Syn into mitochondria (Lu et al., 2013), whereas other studies suggested that $\alpha$ Syn induces loss of function of VDAC in vitro in a voltage-dependent manner, leading to a reduction in the levels of ATP and ADP that compromise mitochondrial respiration (Rostovtseva et al., 2015). In the context of ALS, aggregates of mutant variants of SOD1 have been observed to accumulate on the OMM through direct interactions with VDAC1 (Israelson et al., 2010) and Bcl-2 (Pedrini et al., 2010), causing VDAC dysfunction leading to altered membrane potential, morphology and protein trafficking in mitochondria. Binding of mutant but not wild-type SOD1 to $\mathrm{Bcl}-2$ induces a conformational change that uncovers its $\mathrm{BH} 3$ (death) domain. These processes lead to an increase in the affinity of Bcl-2 for VDAC, which in turn triggers the closure of the channel (Tan et al., 2013) and ultimately the activation of mitochondrial apoptosis. These steps appear to contribute to the initiation and development of motor neuron loss in ALS (Tafuri et al., 2015).

In the context of Huntington's disease (HD), mutant huntingtin (Htt) has been associated with the opening of mPTP in the inner mitochondrial membrane, triggering the release of cytochrome $c$ and activating apoptosis (Choo et al., 2004). Moreover, changes in mitochondrial membrane potential are mediated by abnormal high levels of intracellular $\mathrm{Ca}^{2+}$ as a result of an excessive release of calcium from the ER following the interaction between $\mathrm{Htt}$ and the InsP3 receptor (IP3R) as well as an increased influx upon NMDAR overstimulation (Damiano et al., 2010). The latter is mediated by polyglutamineexpanded Htt through disruption of the physiological interaction between normal Htt and PSD95, a scaffold protein associated with NMDA-receptor function (Sun et al., 2001; Song et al., 2003). The overactivation of NMDA-receptors may indeed be a key factor in the etiology of $\mathrm{HD}$, in what is known as the excitotoxicity hypothesis that postulates that neuronal degeneration in HD results from a hyperactivation of glutamate receptors following an abnormal glutamatergic neurotransmission (DiFiglia, 1990). Injection of NMDA agonists into the striatum of rats induced indeed the degeneration of GABAergic neurons in a pattern reminiscent of the pathology of HD (Brouillet et al., 1999).

Alzheimer's disease is also associated with impairment of the cholinergic pathway in the cerebral cortex and basal forebrain, which involves two main classes of receptors, muscarinic (mAChR) and nicotinic acetylcholine receptors (nAChR) (Sarter and Paolone, 2011; Maurer and Williams, 2017). A decrease in the number of $\mathrm{nAChRs}$ in $\mathrm{AD}$ results from the loss of forebrain cholinergic neurons and a cholinergic presynaptic denervation (Hampel et al., 2018). It has been postulated that under physiological conditions, $A \beta 42$ may enhance synaptic plasticity and memory through the stimulation of $\alpha 7$ nAChR (Puzzo et al., 2015). Under pathological conditions, however, accumulation of aggregates of $\mathrm{A} \beta$ would lead to the internalization and impairment of $\alpha 7 \mathrm{AChR}$ in a negative feedback loop, ultimately resulting in synaptic alteration and loss of memory. Evidence suggests that the complex formed between $\mathrm{A} \beta$ and $\alpha 7 \mathrm{nAChR}$ would be able to induce tau hyperphosphorylation (Wang et al., 2003) and promote plaque formation (Nagele et al., 2003; Dineley et al., 2007), which are both hallmarks of $\mathrm{AD}$. In order to compensate for the internalization of the $A \beta-\alpha 7$ nAChR complex, $\alpha 7 \mathrm{nAChR}$ is upregulated (Shen and $\mathrm{Wu}, 2015$ ) with further internalization of the complex leading to the accumulation of $\mathrm{A} \beta$, the overwhelming of the lysosomes and ultimately neuronal lysis (Palop and Mucke, 2010). In addition to an A $\beta$-dependent internalization of $\alpha 7 \mathrm{nAChR}$, upregulation of $\alpha 7 \mathrm{nAChR}$ in the membrane may result in elevated $\mathrm{Ca}^{2}+$ influx, further contributing to neurotoxicity (Liu et al., 2015b). Interestingly, administration of $\alpha 7 \mathrm{nAChR}$ antagonists to rats rescued learning deficits associated with overactivation of the receptors (Burke et al., 2014), hinting at a possible therapeutic opportunity for overstimulated $\alpha 7 \mathrm{nAChRs}$ in $\mathrm{AD}$.

\section{CONCLUSION}

In summary, there is growing evidence about the key relevance of the membrane interaction by misfolded protein oligomers in PMDs. Two principal mechanisms, namely the membrane disruption and the receptor binding, are supported by extensive experimental evidence. It remains, however, difficult to identify the dominant mechanism of toxicity in PMDs, primarily owing to the heterogeneous and transient nature of misfolded protein oligomers. These species have the ability to interact with a variety of cellular membranes and membrane proteins, with affinities that can be modulated by several factors, including the properties of the membrane (Chaudhary et al., 2016; OropesaNuñez et al., 2016; Bode et al., 2019) and the lipid composition (Evangelisti et al., 2012; Sciacca et al., 2020). The level of 
biological complexity associated with these processes, therefore, poses tremendous challenges in the quest of identifying effective therapeutic strategies to suppress the cellular toxicity in PMDs, as these conditions are associated with various imbalances in cellular homeostasis, and their initiation or propagation can be triggered by multiple concurring factors.

\section{AUTHOR CONTRIBUTIONS}

MG-G, GF, and AD contributed to drafting different parts of the manuscript. All authors revised the manuscript critically for important intellectual content and approved the final version.

\section{REFERENCES}

Abedini, A., Plesner, A., Cao, P., Ridgway, Z., Zhang, J., Tu, L.-H., et al. (2016). Time-resolved studies define the nature of toxic IAPP intermediates, providing insight for anti-amyloidosis therapeutics. eLife 5:e12977. doi: 10.7554/eLife. 12977

Alberdi, E., Sánchez-Gómez, M. V., Cavaliere, F., Pérez-Samartín, A., Zugaza, J. L., Trullas, R., et al. (2010). Amyloid $\beta$ oligomers induce $\mathrm{Ca}^{2+}$ dysregulation and neuronal death through activation of ionotropic glutamate receptors. Cell. Calcium 47, 264-272. doi: 10.1016/j.ceca.2009.12.010

Angelova, P. R., Choi, M. L., Berezhnov, A. V., Horrocks, M. H., Hughes, C. D., De, S., et al. (2020a). Alpha synuclein aggregation drives ferroptosis: an interplay of iron, calcium and lipid peroxidation. Cell. Death Differ. 27, 2781-2796. doi: 10.1038/s41418-020-0542-z

Angelova, P. R., Esteras, N., and Abramov, A. Y. (2020b). Mitochondria and lipid peroxidation in the mechanism of neurodegeneration: finding ways for prevention. Med. Res. Rev. doi: 10.1002/med.21712

Angelova, P. R., Ludtmann, M. H. R., Horrocks, M. H., Negoda, A., Cremades, N., Klenerman, D., et al. (2016). $\mathrm{Ca}^{2+}$ is a key factor in $\alpha$-synucleininduced neurotoxicity. J. Cell. Sci. 129, 1792-1801. doi: 10.1242/jcs.18 0737

Attwell, D., and Laughlin, S. B. (2001). An energy budget for signaling in the grey matter of the brain. J. Cereb. Blood Flow Metabol. 21, 1133-1145. doi: 10.1097/00004647-200110000-00001

Banerjee, K., Sinha, M., Pham, C. L. L., Jana, S., Chanda, D., Cappai, R., et al. (2010). $\alpha$-Synuclein induced membrane depolarization and loss of phosphorylation capacity of isolated rat brain mitochondria: implications in parkinson's disease. FEBS Lett. 584, 1571-1576. doi: 10.1016/j.febslet.2010.03.012

Bhat, A. H., Dar, K. B., Anees, S., Zargar, M. A., Masood, A., Sofi, M. A., et al. (2015). Oxidative stress, mitochondrial dysfunction and neurodegenerative diseases; a mechanistic insight. Biomed. Pharmacother. 74, 101-110. doi: 10.1016/j.biopha. 2015.07.025

Birol, M., Kumar, S., Rhoades, E., and Miranker, A. D. (2018). Conformational switching within dynamic oligomers underpins toxic gain-of-function by diabetes-associated amyloid. Nat. Commun. 9:1312. doi: 10.1038/s41467-01803651-9

Bode, D. C., Baker, M. D., and Viles, J. H. (2017). Ion channel formation by amyloid- $\beta 42$ oligomers but not amyloid- $\beta 40$ in cellular membranes. J. Biol. Chem. 292, 1404-1413. doi: 10.1074/jbc.M116.762526

Bode, D. C., Freeley, M., Nield, J., Palma, M., and Viles, J. H. (2019). Amyloid$\beta$ oligomers have a profound detergent-like effect on lipid membrane bilayers, imaged by atomic force and electron microscopy. J. Biol. Chem. 294, 7566-7572. doi: 10.1074/jbc.AC118.007195

Bonifati, V., Breedveld, G. J., Squitieri, F., Vanacore, N., Brustenghi, P., Harhangi, B. S., et al. (2002). Localization of autosomal recessive early-onset parkinsonism to chromosome 1p36 (PARK7) in an independent dataset. Annals Neurol. 51, 253-256. doi: 10.1002/ana.10106

Britti, E., Ros, J., Esteras, N., and Abramov, A. Y. (2020). Tau inhibits mitochondrial calcium efflux and makes neurons vulnerable to calcium-induced cell death. Cell. Calcium 86:102150. doi: 10.1016/j.ceca.2019.102150

\section{FUNDING}

This work was supported by grants from the European Research Council (BioDisOrder - 819644), the UK Medical Research Council (MR/N000676/1), the UK Biotechnology and Biological Sciences Research Council (BB/M011178/1), and the St John's College of the University of Cambridge.

\section{ACKNOWLEDGMENTS}

We apologize to the many authors of studies that we could not discuss because of space limitations.

Brody, A. H., and Strittmatter, S. M. (2018). Synaptotoxic signaling by amyloid beta oligomers in alzheimer's disease through prion protein and mGluR5. Adv. Pharmacol. 82, 293-323. doi: 10.1016/bs.apha.2017.09.007

Brouillet, E., Condé, F., Beal, M. F., and Hantraye, P. (1999). Replicating huntington's disease phenotype in experimental animals. Prog. Neurobiol. 59, 427-468. doi: 10.1016/S0301-0082(99)00005-2

Burke, D. A., Heshmati, P., Kholdebarin, E., and Levin, E. D. (2014). Decreasing nicotinic receptor activity and the spatial learning impairment caused by the NMDA glutamate antagonist dizocilpine in rats. Eur. J. Pharmacol. 741, 132-139. doi: 10.1016/j.ejphar.2014.07.030

Camilleri, A., Ghio, S., Caruana, M., Weckbecker, D., Schmidt, F., Kamp, F., et al. (2020). Tau-induced mitochondrial membrane perturbation is dependent upon cardiolipin. Biochim. Biophys. Acta Biomembr. 1862:183064. doi: 10.1016/ j.bbamem.2019.183064

Camilleri, A., Zarb, C., Caruana, M., Ostermeier, U., Ghio, S., Högen, T., et al. (2013). Mitochondrial membrane permeabilisation by amyloid aggregates and protection by polyphenols. Biochim. Biophys. Acta 1828, 2532-2543. doi: 10. 1016/j.bbamem.2013.06.026

Carrì, M. T., Ferri, A., Battistoni, A., Famhy, L., Gabbianelli, R., Poccia, F., et al. (1997). Expression of a Cu,Zn superoxide dismutase typical of familial amyotrophic lateral sclerosis induces mitochondrial alteration and increase of cytosolic Ca2+ concentration in transfected neuroblastoma SH-SY5Y cells. FEBS Lett. 414, 365-368. doi: 10.1016/s0014-5793(97)01051-x

Cascella, R., Perni, M., Chen, S. W., Fusco, G., Cecchi, C., Vendruscolo, M., et al. (2019). Probing the origin of the toxicity of oligomeric aggregates of $\alpha$-synuclein with antibodies. ACS Chem. Biol. 14, 1352-1362. doi: 10.1021/acschembio. $9 \mathrm{~b} 00312$

Casley, C. S., Canevari, L., Land, J. M., Clark, J. B., and Sharpe, M. A. (2002). $\beta$-Amyloid inhibits integrated mitochondrial respiration ?and key enzyme activities. J. Neurochem. 80, 91-100. doi: 10.1046/j.0022-3042.2001.00681.x

Casley, C. S., Lakics, V., Lee, H.-G., Broad, L. M., Day, T. A., Cluett, T., et al. (2009). Up-regulation of astrocyte metabotropic glutamate receptor 5 by amyloid- $\beta$ peptide. Brain Res. 1260, 65-75. doi: 10.1016/j.brainres.2008.12.082

Cenini, G., Lloret, A., and Cascella, R. (2019). Oxidative stress in neurodegenerative diseases: from a mitochondrial point of view. Oxidative Med. Cell. Longevity 2019:2105607. doi: 10.1155/2019/2105607

Chaudhary, H., Iyer, A., Subramaniam, V., and Claessens, M. M. A. E. (2016). $\alpha$-Synuclein oligomers stabilize pre-existing defects in supported bilayers and propagate membrane damage in a fractal-like pattern. Langmuir 32, 1182711836. doi: 10.1021/acs.langmuir.6b02572

Cheignon, C., Tomas, M., Bonnefont-Rousselot, D., Faller, P., Hureau, C., Collin, F. et al. (2018). Oxidative stress and the amyloid beta peptide in Alzheimer's disease. Redox Biol. 14, 450-464. doi: 10.1016/j.redox.2017.10.014

Chen, S. W., Drakulic, S., Deas, E., Ouberai, M., Aprile, F. A., Arranz, R., et al. (2015). Structural characterization of toxic oligomers that are kinetically trapped during $\alpha$-synuclein fibril formation. Proc. Natl. Acad. Sci. 112:E1994. doi: $10.1073 /$ pnas. 1421204112

Chiti, F., and Dobson, C. M. (2017). Protein misfolding, amyloid formation, and human disease: a summary of progress over the last decade. Ann. Rev. Biochem. 86, 27-68. doi: 10.1146/annurev-biochem-061516-045115 
Choi, M. L., and Gandhi, S. (2018). Crucial role of protein oligomerization in the pathogenesis of Alzheimer's and Parkinson's diseases. FEBS J. 285, 3631-3644. doi: $10.1111 /$ febs. 14587

Choo, Y. S., Johnson, G. V. W., MacDonald, M., Detloff, P. J., and Lesort, M. (2004). Mutant huntingtin directly increases susceptibility of mitochondria to the calcium-induced permeability transition and cytochrome c release. Hum. Mol. Genet. 13, 1407-1420. doi: 10.1093/hmg/ddh162

Corbett, G. T., Wang, Z., Hong, W., Colom-Cadena, M., Rose, J., Liao, M., et al. (2020). PrP is a central player in toxicity mediated by soluble aggregates of neurodegeneration-causing proteins. Acta Neuropathol. 139, 503-526. doi: 10. 1007/s00401-019-02114-9

Dalfó, E., and Ferrer, I. (2008). Early alpha-synuclein lipoxidation in neocortex in lewy body diseases. Neurobiol. Aging 29, 408-417. doi: 10.1016/j. neurobiolaging.2006.10.022

Damiano, M., Galvan, L., Déglon, N., and Brouillet, E. (2010). Mitochondria in huntington's disease. Biochim.t Biophys. Acta 1802, 52-61. doi: 10.1016/j.bbadis. 2009.07.012

De Simone, A., Esposito, L., Pedone, C., and Vitagliano, L. (2008). Insights into stability and toxicity of amyloid-like oligomers by replica exchange molecular dynamics analyses. Biophys. J. 95, 1965-1973. doi: 10.1529/biophysj.108.129213

Deng, H.-X., Shi, Y., Furukawa, Y., Zhai, H., Fu, R., Liu, E., et al. (2006). Conversion to the amyotrophic lateral sclerosis phenotype is associated with intermolecular linked insoluble aggregates of SOD1 in mitochondria. Proc. Natl. Acad. Sci. US A. 103, 7142-7147. doi: 10.1073/pnas.0602046103

Devi, L., Raghavendran, V., Prabhu, B. M., Avadhani, N. G., and Anandatheerthavarada, H. K. (2008). Mitochondrial import and accumulation of alpha-synuclein impair complex I in human dopaminergic neuronal cultures and Parkinson disease brain. J. Biol. Chem. 283, 9089-9100. doi: 10.1074/jbc.M710012200

DiFiglia, M. (1990). Excitotoxic injury of the neostriatum: a model for Huntington's disease. Trends Neurosci. 13, 286-289. doi: 10.1016/0166-2236(90)90111-M

Dineley, K. T., Hogan, D., Zhang, W.-R., and Taglialatela, G. (2007). Acute inhibition of calcineurin restores associative learning and memory in Tg2576 APP transgenic mice. Neurobiol. Learning Mem. 88, 217-224. doi: 10.1016/j. nlm.2007.03.010

Elías-Wolff, F., Lindén, M., Lyubartsev, A. P., and Brandt, E. G. (2019). Curvature sensing by cardiolipin in simulated buckled membranes. Soft Matter 15, 792802. doi: 10.1039/C8SM02133C

Evangelisti, E., Cecchi, C., Cascella, R., Sgromo, C., Becatti, M., Dobson, C. M., et al. (2012). Membrane lipid composition and its physicochemical properties define cell vulnerability to aberrant protein oligomers. J. Cell. Sci. 125, 2416-2427. doi: $10.1242 /$ jcs.098434

Farrugia, M. Y., Caruana, M., Ghio, S., Camilleri, A., Farrugia, C., Cauchi, R. J., et al. (2020). Toxic oligomers of the amyloidogenic HypF-N protein form pores in mitochondrial membranes. Sci. Rep. 10:17733. doi: 10.1038/s41598-020-74 $841-\mathrm{z}$

Feng, L. R., Federoff, H. J., Vicini, S., and Maguire-Zeiss, K. A. (2010). Alphasynuclein mediates alterations in membrane conductance: a potential role for alpha-synuclein oligomers in cell vulnerability. Eur. J. Neurosci. 32, 10-17. doi: 10.1111/j.1460-9568.2010.07266.x

Ferreira, D. G., Temido-Ferreira, M., Vicente Miranda, H., Batalha, V. L., Coelho, J. E., Szegö, ÉM., et al. (2017). $\alpha$-synuclein interacts with PrPC to induce cognitive impairment through mGluR5 and NMDAR2B. Nat. Neurosci. 20, 1569-1579. doi: 10.1038/nn.4648

Freir, D. B., Nicoll, A. J., Klyubin, I., Panico, S., Mc Donald, J. M., Risse, E., et al. (2011). Interaction between prion protein and toxic amyloid $\beta$ assemblies can be therapeutically targeted at multiple sites. Nat. Commun. 2, 336-336. doi: $10.1038 /$ ncomms1341

Fusco, G., Chen, S. W., Williamson, P. T. F., Cascella, R., Perni, M., Jarvis, J. A., et al. (2017). Structural basis of membrane disruption and cellular toxicity by $\alpha$-synuclein oligomers. Science 358, 1440-1443. doi: 10.1126/science.aan6160

Ganjam, G. K., Bolte, K., Matschke, L. A., Neitemeier, S., Dolga, A. M., Höllerhage, M., et al. (2019). Mitochondrial damage by $\alpha$-synuclein causes cell death in human dopaminergic neurons. Cell. Death Dis. 10:865. doi: 10.1038/s41419019-2091-2

Ghio, S., Camilleri, A., Caruana, M., Ruf, V. C., Schmidt, F., Leonov, A., et al. (2019). Cardiolipin promotes pore-forming activity of alpha-synuclein oligomers in mitochondrial membranes. ACS Chem. Neurosci. 10, 3815-3829. doi: 10.1021/acschemneuro.9b00320

Gilks, W. P., Abou-Sleiman, P. M., Gandhi, S., Jain, S., Singleton, A., Lees, A. J., et al. (2005). A common LRRK2 mutation in idiopathic Parkinson's disease. Lancet 365, 415-416. doi: 10.1016/S0140-6736(05)17830-1

Glabe, C. G. (2006). Common mechanisms of amyloid oligomer pathogenesis in degenerative disease. Neurobiol. Aging 27, 570-575. doi: 10.1016/j. neurobiolaging.2005.04.017

Guardia-Laguarta, C., Area-Gomez, E., Rüb, C., Liu, Y., Magrané, J., Becker, D., et al. (2014). $\alpha$-Synuclein is localized to mitochondria-associated ER membranes. J. Neurosci. 34, 249-259. doi: 10.1523/jneurosci.2507-13.2014

Gurlo, T., Ryazantsev, S., Huang, C.-J., Yeh, M. W., Reber, H. A., Hines, O. J., et al. (2010). Evidence for proteotoxicity in beta cells in type 2 diabetes: toxic islet amyloid polypeptide oligomers form intracellularly in the secretory pathway. Am. J. Pathol. 176, 861-869. doi: 10.2353/ajpath.2010.090532

Haas, L. T., Kostylev, M. A., and Strittmatter, S. M. (2014). Therapeutic molecules and endogenous ligands regulate the interaction between brain cellular prion protein (PrPC) and metabotropic glutamate receptor 5 (mGluR5). J. Biol. Chem. 289, 28460-28477. doi: 10.1074/jbc.M114.584342

Haas, L. T., Salazar, S. V., Kostylev, M. A., Um, J. W., Kaufman, A. C., Strittmatter, S. M. et al. (2016). Metabotropic glutamate receptor 5 couples cellular prion protein to intracellular signalling in Alzheimer's disease. Brain 139, 526-546. doi: 10.1093/brain/awv356

Hamilton, A., Esseltine, J. L., DeVries, R. A., Cregan, S. P., and Ferguson, S. S. G. (2014). Metabotropic glutamate receptor 5 knockout reduces cognitive impairment and pathogenesis in a mouse model of Alzheimer's disease. Mol. Brain 7, 40-40. doi: 10.1186/1756-6606-7-40

Hampel, H., Mesulam, M. M., Cuello, A. C., Farlow, M. R., Giacobini, E., Grossberg, G. T., et al. (2018). The cholinergic system in the pathophysiology and treatment of Alzheimer's disease. Brain 141, 1917-1933. doi: 10.1093/brain/awy132

Hartl, F. U. (2017). Protein misfolding diseases. Ann. Rev.Biochem. 86, 21-26. doi: 10.1146/annurev-biochem-061516-044518

Higgins, C. M. J., Jung, C., Ding, H., and Xu, Z. (2002). Mutant Cu, Zn superoxide dismutase that causes motoneuron degeneration is present in mitochondria in the CNS. J. Neurosci. 22:RC215. doi: 10.1523/JNEUROSCI.22-06-j0001.2002

Hirano, A., Donnenfeld, H., Sasaki, S., and Nakano, I. (1984). Fine structural observations of neurofilamentous changes in amyotrophic lateral sclerosis. J. Neuropathol. Exp. Neurol. 43, 461-470. doi: 10.1097/00005072-19840900000001

Horvath, S. E., and Daum, G. (2013). Lipids of mitochondria. Prog. Lipid Res. 52, 590-614. doi: 10.1016/j.plipres.2013.07.002

Hsieh, H., Boehm, J., Sato, C., Iwatsubo, T., Tomita, T., Sisodia, S., et al. (2006). AMPAR removal underlies Abeta-induced synaptic depression and dendritic spine loss. Neuron 52, 831-843. doi: 10.1016/j.neuron.2006.10.035

Hsu, L. J., Sagara, Y., Arroyo, A., Rockenstein, E., Sisk, A., Mallory, M., et al. (2000). $\alpha$-Synuclein promotes mitochondrial deficit and oxidative stress. Am. J. Pathol. 157, 401-410. doi: 10.1016/S0002-9440(10)64553-1

Hu, N.-W., Nicoll, A. J., Zhang, D., Mably, A. J., O’Malley, T., Purro, S. A., et al. (2014). mGlu5 receptors and cellular prion protein mediate amyloid- $\beta$ facilitated synaptic long-term depression in vivo. Nat. Commun. 5, 3374-3374. doi: $10.1038 /$ ncomms 4374

Iqbal, K., Liu, F., Gong, C. X., and Grundke-Iqbal, I. (2010). Tau in Alzheimer disease and related tauopathies. Curr. Alzheimer Res. 7, 656-664. doi: 10.2174/ 156720510793611592

Israelson, A., Arbel, N., Da Cruz, S., Ilieva, H., Yamanaka, K., Shoshan-Barmatz, V., et al. (2010). Misfolded mutant SOD1 directly inhibits VDAC1 conductance in a mouse model of inherited ALS. Neuron 67, 575-587. doi: 10.1016/j.neuron. 2010.07.019

Jang, H., Arce, F. T., Ramachandran, S., Capone, R., Azimova, R., Kagan, B. L., et al. (2010). Truncated $\beta$-amyloid peptide channels provide an alternative mechanism for Alzheimer's disease and down syndrome. Proc. Natl. Acad. Sci. 107:6538. doi: 10.1073/pnas.0914251107

Joshi, G., Perluigi, M., Sultana, R., Agrippino, R., Calabrese, V., Butterfield, D. A. et al. (2006). In vivo protection of synaptosomes by ferulic acid ethyl ester (FAEE) from oxidative stress mediated by 2,2-azobis(2amidino-propane)dihydrochloride (AAPH) or $\mathrm{Fe}(2+) / \mathrm{H}(2) \mathrm{O}(2)$ : insight into mechanisms of neuroprotection and relevance to oxidative stress-related 
neurodegenerative disorders. Neurochem. Int. 48, 318-327. doi: 10.1016/j. neuint.2005.11.006

Kayed, R., Pensalfini, A., Margol, L., Sokolov, Y., Sarsoza, F., Head, E., et al. (2009). Annular protofibrils are a structurally and functionally distinct type of amyloid oligomer. J. Biol. Chem. 284, 4230-4237. doi: 10.1074/jbc.M808591200

Kegulian, N. C., Sankhagowit, S., Apostolidou, M., Jayasinghe, S. A., Malmstadt, N., Butler, P. C., et al. (2015). Membrane curvature-sensing and curvature-inducing activity of islet amyloid polypeptide and its implications for membrane disruption. J. Biol. Chem. 290, 25782-25793. doi: 10.1074/jbc.M115.659797

Kim, H.-Y., Cho, M.-K., Kumar, A., Maier, E., Siebenhaar, C., Becker, S., et al. (2009). Structural properties of pore-forming oligomers of $\alpha$-synuclein. J. Am. Chem. Soc. 131, 17482-17489. doi: 10.1021/ja9077599

Kim, S. D., Allen, N. E., Canning, C. G., and Fung, V. S. C. (2018). "Parkinson disease," in Handbook of Clinical Neurology, eds B. L. Day and S. R. Lord (Amsterdam, Netherlands: Elsevier), 173-193.

Klingenberg, M. (2009). Cardiolipin and mitochondrial carriers. Biochim. Biophys. Acta 1788, 2048-2058. doi: 10.1016/j.bbamem.2009.06.007

La Rosa, C., Scalisi, S., Lolicato, F., Pannuzzo, M., and Raudino, A. (2016). Lipidassisted protein transport: A diffusion-reaction model supported by kinetic experiments and molecular dynamics simulations. J. Chem. Phys. 144:184901. doi: $10.1063 / 1.4948323$

Lashuel, H. A. (2005). Membrane permeabilization: a common mechanism in protein-misfolding diseases. Sci. Aging Knowl. Environ. 2005:e28. doi: 10.1126/ sageke.2005.38.pe28

Lashuel, H. A., Hartley, D., Petre, B. M., Walz, T., and Lansbury, P. T. (2002). Amyloid pores from pathogenic mutations. Nature 418, 291-291. doi: 10.1038/ 418291a

Laurén, J., Gimbel, D. A., Nygaard, H. B., Gilbert, J. W., and Strittmatter, S. M. (2009). Cellular prion protein mediates impairment of synaptic plasticity by amyloid-beta oligomers. Nature 457, 1128-1132. doi: 10.1038/nature 07761

Li, C., and Götz, J. (2018). Pyk2 is a novel tau tyrosine kinase that is regulated by the tyrosine kinase fyn. J. Alzheimer's Dis. 64, 205-221. doi: 10.3233/JAD- 180054

Li, F., and Tsien, J. Z. (2009). Memory and the NMDA receptors. N.Eng. J. Med. 361, 302-303. doi: 10.1056/NEJMcibr0902052

Liang, J., Kulasiri, D., and Samarasinghe, S. (2017). Computational investigation of Amyloid- $\beta$-induced location- and subunit-specific disturbances of NMDAR at hippocampal dendritic spine in Alzheimer's disease. PLoS One 12:e0182743. doi: 10.1371/journal.pone.0182743

Lim, D., Iyer, A., Ronco, V., Grolla, A. A., Canonico, P. L., Aronica, E., et al. (2013). Amyloid beta deregulates astroglial mGluR5-mediated calcium signaling via calcineurin and Nf-kB. Glia 61, 1134-1145. doi: 10.1002/glia.22502

Lin, H. A. I., Bhatia, R., and Lal, R. (2001). Amyloid $\beta$ protein forms ion channels: implications for Alzheimer's disease pathophysiology. FASEB J. 15, 2433-2444. doi: 10.1096/fj.01-0377com

Lin, M. T., and Beal, M. F. (2006). Mitochondrial dysfunction and oxidative stress in neurodegenerative diseases. Nature 443, 787-795. doi: 10.1038/nature05292

Liu, L., Komatsu, H., Murray, I. V. J., and Axelsen, P. H. (2008). Promotion of amyloid $\beta$ Protein misfolding and fibrillogenesis by a lipid oxidation product. J. Mol. Biol. 377, 1236-1250. doi: 10.1016/j.jmb.2008.01.057

Liu, L., Zhang, K., Tan, L., Chen, Y.-H., and Cao, Y.-P. (2015a). Alterations in cholesterol and ganglioside GM1 content of lipid rafts in platelets from patients with alzheimer disease. Alzheimer Dis. Assoc.Disord. 29, 63-69. doi: 10.1097/ wad.0000000000000041

Liu, Y., Wu, D., Song, F., Zhu, C., Hui, Y., Zhu, Q., et al. (2015b). Activation of a7 nicotinic acetylcholine receptors prevents monosodium iodoacetateinduced osteoarthritis in rats. Cell. Physiol. Biochem. 35, 627-638. doi: 10.1159/ 000369724

Lu, L., Zhang, C., Cai, Q., Lu, Q., Duan, C., Zhu, Y., et al. (2013). Voltagedependent anion channel involved in the $\alpha$-synuclein-induced dopaminergic neuron toxicity in rats. Acta Biochim. Biophys. Sinica 45, 170-178. doi: 10.1093/ abbs/gms114

Luth, E. S., Stavrovskaya, I. G., Bartels, T., Kristal, B. S., and Selkoe, D. J. (2014). Soluble, prefibrillar $\alpha$-synuclein oligomers promote complex I-dependent, $\mathrm{Ca}^{2+}$-induced mitochondrial dysfunction. J. Biol. Chem. 289, 21490-21507. doi: 10.1074/jbc.M113.545749

Mannini, B., Mulvihill, E., Sgromo, C., Cascella, R., Khodarahmi, R., Ramazzotti, M., et al. (2014). Toxicity of protein oligomers is rationalized by a function combining size and surface hydrophobicity. ACS Chem. Biol. 9, 2309-2317. doi: 10.1021/cb500505m

Mattiazzi, M., D’Aurelio, M., Gajewski, C. D., Martushova, K., Kiaei, M., Beal, M. F., et al. (2002). Mutated human SOD1 causes dysfunction of oxidative phosphorylation in mitochondria of transgenic mice. J. Biol. Chem. 277, 2962629633. doi: 10.1074/jbc.M203065200

Mattson, M. P. (2007). Calcium and neurodegeneration. Aging Cell. 6, 337-350. doi: 10.1111/j.1474-9726.2007.00275.x

Maurer, S. V., and Williams, C. L. (2017). The cholinergic system modulates memory and hippocampal plasticity via its interactions with non-neuronal cells. Front. Immunol. 8:1489. doi: 10.3389/fimmu.2017.01489

Menzies, F. M., Cookson, M. R., Taylor, R. W., Turnbull, D. M., ChrzanowskaLightowlers, Z. M. A., Dong, L., et al. (2002). Mitochondrial dysfunction in a cell culture model of familial amyotrophic lateral sclerosis. Brain 125, 1522-1533. doi: 10.1093/brain/awf167

Meratan, A. A., Ghasemi, A., and Nemat-Gorgani, M. (2011). membrane integrity and amyloid cytotoxicity: a model study involving mitochondria and lysozyme fibrillation products. J. Mol. Biol. 409, 826-838. doi: 10.1016/j.jmb.2011.04.045

Meratan, A. A., and Nemat-Gorgani, M. (2012). Mitochondrial membrane permeabilization upon interaction with lysozyme fibrillation products: role of mitochondrial heterogeneity. Biochim. Biophys. Acta 1818, 2149-2157. doi: 10. 1016/j.bbamem.2012.04.020

Michalska, P., and León, R. (2020). When it comes to an end: oxidative stress crosstalk with protein aggregation and neuroinflammation induce neurodegeneration. Antioxidants 9:740. doi: 10.3390/antiox9080740

Molander-Melin, M., Blennow, K., Bogdanovic, N., Dellheden, B., Månsson, J.-E., and Fredman, P. (2005). Structural membrane alterations in Alzheimer brains found to be associated with regional disease development; increased density of gangliosides GM1 and GM2 and loss of cholesterol in detergent-resistant membrane domains. J. Neurochem. 92, 171-182. doi: 10.1111/j.1471-4159.2004. 02849.x

Morin, N., Grégoire, L., Morissette, M., Desrayaud, S., Gomez-Mancilla, B., Gasparini, F., et al. (2013). MPEP, an mGlu5 receptor antagonist, reduces the development of l-DOPA-induced motor complications in de novo parkinsonian monkeys: biochemical correlates. Neuropharmacology 66, 355-364. doi: 10. 1016/j.neuropharm.2012.07.036

Mutisya, E. M., Bowling, A. C., and Beal, M. F. (1994). Cortical cytochrome oxidase activity is reduced in Alzheimer's disease. J. Neurochem. 63, 2179-2184. doi: 10.1046/j.1471-4159.1994.63062179.x

Nagele, R. G., D’Andrea, M. R., Lee, H., Venkataraman, V., and Wang, H.-Y. (2003). Astrocytes accumulate $A \beta 42$ and give rise to astrocytic amyloid plaques in Alzheimer disease brains. Brain Res. 971, 197-209. doi: 10.1016/S00068993(03)02361-8

Nakamura, K. (2013). $\alpha$-Synuclein and mitochondria: partners in crime? Neurotherapeutics 10, 391-399. doi: 10.1007/s13311-013-0182-9

Nichols, W. C., Pankratz, N., Hernandez, D., Paisán-Ruíz, C., Jain, S., Halter, C. A., et al. (2005). Genetic screening for a single common $L R R K 2$ mutation in familial Parkinson's disease. Lancet 365, 410-412. doi: 10.1016/S0140-6736(05)17828-3

Ohnishi, T., Yanazawa, M., Sasahara, T., Kitamura, Y., Hiroaki, H., Fukazawa, Y., et al. (2015). Na, K-ATPase $\alpha 3$ is a death target of Alzheimer patient amyloid- $\beta$ assembly. Proc. Natl. Acad. Sci. U S A. 112, E4465-E4474. doi: 10.1073/pnas. 1421182112

Oladzad Abbasabadi, A., Javanian, A., Nikkhah, M., Meratan, A. A., Ghiasi, P., and Nemat-Gorgani, M. (2013). Disruption of mitochondrial membrane integrity induced by amyloid aggregates arising from variants of SOD1. Int. J. Biol. Macromol. 61, 212-217. doi: 10.1016/j.ijbiomac.2013.07.007

Oren, O., Ben Zichri, S., Taube, R., Jelinek, R., and Papo, N. (2020). A $\beta 42$ double mutant inhibits A $\beta 42$-induced plasma and mitochondrial membrane disruption in artificial membranes, isolated organs, and intact cells. ACS Chem. Neurosci. 11, 1027-1037. doi: 10.1021/acschemneuro.9b00638

Oropesa-Nuñez, R., Seghezza, S., Dante, S., Diaspro, A., Cascella, R., Cecchi, C., et al. (2016). Interaction of toxic and non-toxic HypF-N oligomers with lipid bilayers investigated at high resolution with atomic force microscopy. Oncotarget 7, 44991-45004. doi: 10.18632/oncotarget.10449

Padurariu, M., Ciobica, A., Hritcu, L., Stoica, B., Bild, W., and Stefanescu, C. (2010). Changes of some oxidative stress markers in the serum of patients with mild cognitive impairment and Alzheimer's disease. Neurosci. Lett. 469, 6-10. doi: 10.1016/j.neulet.2009.11.033 
Palop, J. J., and Mucke, L. (2010). Amyloid-beta-induced neuronal dysfunction in Alzheimer's disease: from synapses toward neural networks. Nat. Neurosci. 13, 812-818. doi: 10.1038/nn.2583

Pannuzzo, M., Raudino, A., Milardi, D., La Rosa, C., and Karttunen, M. (2013). $\alpha$ Helical structures drive early stages of self-assembly of amyloidogenic amyloid polypeptide aggregate formation in membranes. Sci. Rep. 3:2781. doi: 10.1038/ srep02781

Pariary, R., Bhattacharyya, D., and Bhunia, A. (2019). Mitochondrial-membrane association of $\alpha$-synuclein: Pros and cons in consequence of Parkinson's disease pathophysiology. Gene. Rep. 16;100423. doi: 10.1016/j.genrep.2019.100423

Pedrini, S., Sau, D., Guareschi, S., Bogush, M., Brown, R. H. Jr., Naniche, N., et al. (2010). ALS-linked mutant SOD1 damages mitochondria by promoting conformational changes in Bcl-2. Hum. Mol. Genet. 19, 2974-2986. doi: 10. 1093/hmg/ddq202

Picklo, M. J. Sr., and Montine, T. J. (2007). Mitochondrial effects of lipid-derived neurotoxins. J. Alzheimers Dis. 12, 185-193. doi: 10.3233/jad-2007-12209

Pilkington, A. W., Donohoe, G. C., Akhmedov, N. G., Ferrebee, T., Valentine, S. J., and Legleiter, J. (2019). Hydrogen peroxide modifies a $\beta$-membrane interactions with implications for A $\beta 40$ aggregation. Biochemistry 58, 2893-2905. doi: 10. 1021/acs.biochem.9b00233

Price, D. L., Rockenstein, E., Ubhi, K., Phung, V., MacLean-Lewis, N., Askay, D., et al. (2010). Alterations in mGluR5 expression and signaling in Lewy body disease and in transgenic models of alpha-synucleinopathy-implications for excitotoxicity. PloS One 5:e14020. doi: 10.1371/journal.pone.0014020

Purro, S. A., Nicoll, A. J., and Collinge, J. (2018). Prion protein as a toxic acceptor of amyloid- $\beta$ oligomers. Biol. Psychiatry 83, 358-368. doi: 10.1016/j.biopsych. 2017.11.020

Puzzo, D., Gulisano, W., Arancio, O., and Palmeri, A. (2015). The keystone of Alzheimer pathogenesis might be sought in A $\beta$ physiology. Neuroscience 307, 26-36. doi: 10.1016/j.neuroscience.2015.08.039

Quist, A., Doudevski, I., Lin, H., Azimova, R., Ng, D., Frangione, B., et al. (2005). Amyloid ion channels: a common structural link for protein-misfolding disease. Proc. Natl. Acad. Sci. U S A. 102, 10427-10432. doi: 10.1073/pnas.0502066102

Rauch, J. N., Luna, G., Guzman, E., Audouard, M., Challis, C., Sibih, Y. E., et al. (2020). LRP1 is a master regulator of tau uptake and spread. Nature 580, 381-385. doi: 10.1038/s41586-020-2156-5

Reddy, P. H. (2009). Role of mitochondria in neurodegenerative diseases: mitochondria as a therapeutic target in Alzheimer's disease. CNS Spectrums 14, 8-18. doi: 10.1017/s1092852900024901

Renner, M., Lacor, P. N., Velasco, P. T., Xu, J., Contractor, A., Klein, W. L., et al. (2010). Deleterious effects of amyloid beta oligomers acting as an extracellular scaffold for mGluR5. Neuron 66, 739-754. doi: 10.1016/j.neuron.2010.04.029

Resende, R., Ferreiro, E., Pereira, C., and Resende de Oliveira, C. (2008). Neurotoxic effect of oligomeric and fibrillar species of amyloid-beta peptide 142: Involvement of endoplasmic reticulum calcium release in oligomer-induced cell death. Neuroscience 155, 725-737. doi: 10.1016/j.neuroscience.2008.06.036

Rhein, V., Song, X., Wiesner, A., Ittner, L. M., Baysang, G., Meier, F., et al. (2009). Amyloid-beta and tau synergistically impair the oxidative phosphorylation system in triple transgenic Alzheimer's disease mice. Proc. Natl. Acad. Sci. U S A. 106, 20057-20062. doi: 10.1073/pnas.0905529106

Rostovtseva, T. K., Gurnev, P. A., Protchenko, O., Hoogerheide, D. P., Yap, T. L., Philpott, C. C., et al. (2015). $\alpha$-Synuclein shows high affinity interaction with voltage-dependent anion channel, suggesting mechanisms of mitochondrial regulation and toxicity in parkinson disease. J. Biol. Chem. 290, 18467-18477. doi: 10.1074/jbc.M115.641746

Ruegsegger, C., Maharjan, N., Goswami, A., Filézac de L’Etang, A., Weis, J., Troost, D., et al. (2016). Aberrant association of misfolded SOD1 with $\mathrm{Na}+/ \mathrm{K}+\mathrm{ATPase}-$ $\alpha 3$ impairs its activity and contributes to motor neuron vulnerability in ALS. Acta Neuropathol. 131, 427-451. doi: 10.1007/s00401-015-1510-4

Rui, Y., Gu, J., Yu, K., Hartzell, H. C., and Zheng, J. Q. (2010). Inhibition of AMPA receptor trafficking at hippocampal synapses by beta-amyloid oligomers: the mitochondrial contribution. Mol. Brain 3, 10-10. doi: 10.1186/1756-6606-3-10

Rushworth, J. V., Griffiths, H. H., Watt, N. T., and Hooper, N. M. (2013). Prion protein-mediated toxicity of amyloid- $\beta$ oligomers requires lipid rafts and the transmembrane LRP1. J. Biol. Chem. 288, 8935-8951. doi: 10.1074/jbc.M112. 400358

Salazar, S. V., Gallardo, C., Kaufman, A. C., Herber, C. S., Haas, L. T., Robinson, S., et al. (2017). Conditional deletion of Prnp rescues behavioral and synaptic deficits after disease onset in transgenic Alzheimer's disease. J. Neurosci. 37, 9207-9221. doi: 10.1523/jneurosci.0722-17.2017

Sanchez-Pernaute, R., Wang, J. Q., Kuruppu, D., Cao, L., Tueckmantel, W., Kozikowski, A., et al. (2008). Enhanced binding of metabotropic glutamate receptor type 5 (mGluR5) PET tracers in the brain of parkinsonian primates. NeuroImage 42, 248-251. doi: 10.1016/j.neuroimage.2008.04.170

Sarter, M., and Paolone, G. (2011). Deficits in attentional control: cholinergic mechanisms and circuitry-based treatment approaches. Behav. Neurosci. 125, 825-835. doi: 10.1037/a0026227

Sciacca, M. F., Lolicato, F., Tempra, C., Scollo, F., Sahoo, B. R., Watson, M. D., et al. (2020). Lipid-chaperone hypothesis: a common molecular mechanism of membrane disruption by intrinsically disordered proteins. ACS Chem. Neurosci. 11, 4336-4350. doi: 10.1021/acschemneuro.0c00588

Sciacca, M. F. M., Tempra, C., Scollo, F., Milardi, D., and La Rosa, C. (2018). Amyloid growth and membrane damage: current themes and emerging perspectives from theory and experiments on A $\beta$ and hIAPP. Biochim. Biophys. Acta 1860, 1625-1638. doi: 10.1016/j.bbamem.2018.02.022

Scollo, F., and La Rosa, C. (2020). Amyloidogenic intrinsically disordered proteins: new insights into their self-assembly and their interaction with membranes. Life 10:144. doi: 10.3390/life10080144

Scollo, F., Tempra, C., Lolicato, F., Sciacca, M. F. M., Raudino, A., Milardi, D., et al. (2018). Phospholipids critical micellar concentrations trigger different mechanisms of intrinsically disordered proteins interaction with model membranes. J. Phys. Chem. Lett. 9, 5125-5129. doi: 10.1021/acs.jpclett.8b0 2241

Shen, J., and Wu, J. (2015). Nicotinic cholinergic mechanisms in Alzheimer's disease. Int. Rev. Neurobiol. 124, 275-292. doi: 10.1016/bs.irn.2015.08.002

Sherer, T. B., Betarbet, R., Stout, A. K., Lund, S., Baptista, M., Panov, A. V., et al. (2002). An in vitro model of Parkinson's disease: linking mitochondrial impairment to altered alpha-synuclein metabolism and oxidative damage. J. Neurosci. 22, 7006-7015. doi: 10.1523/JNEUROSCI.22-16-07006.2002

Shrivastava, A. N., Aperia, A., Melki, R., and Triller, A. (2017). Physicopathologic mechanisms involved in neurodegeneration: misfolded proteinplasma membrane interactions. Neuron 95, 33-50. doi: 10.1016/j.neuron.2017. 05.026

Shrivastava, A. N., Kowalewski, J. M., Renner, M., Bousset, L., Koulakoff, A., Melki, R., et al. (2013). $\beta$-amyloid and ATP-induced diffusional trapping of astrocyte and neuronal metabotropic glutamate type-5 receptors. Glia 61, 1673-1686. doi: $10.1002 /$ glia. 22548

Shrivastava, A. N., Redeker, V., Fritz, N., Pieri, L., Almeida, L. G., Spolidoro, M., et al. (2015). $\alpha$-synuclein assemblies sequester neuronal $\alpha 3-\mathrm{Na}+/ \mathrm{K}+-$ ATPase and impair Na+ gradient. EMBO J. 34, 2408-2423. doi: 10.15252/embj. 201591397

Song, C., Zhang, Y., Parsons, C. G., and Liu, Y. F. (2003). Expression of polyglutamine-expanded huntingtin induces tyrosine phosphorylation of n-methyl-D-aspartate receptors. J. Biol. Chem. 278, 33364-33369. doi: 10.1074/ jbc.M304240200

Sun, Y., Savanenin, A., Reddy, P. H., and Liu, Y. F. (2001). Polyglutamineexpanded huntingtin promotes sensitization of N-Methyl-d-aspartate receptors via post-synaptic density 95. J. Biol. Chem. 276, 24713-24718. doi: 10.1074/jbc. M103501200

Swerdlow, R. H., Parks, J. K., Cassarino, D. S., Trimmer, P. A., Miller, S. W., Maguire, D. J., et al. (1998). Mitochondria in sporadic amyotrophic lateral sclerosis. Exp. Neurol. 153, 135-142. doi: 10.1006/exnr.1998.6866

Tafuri, F., Ronchi, D., Magri, F., Comi, G. P., and Corti, S. (2015). SOD1 misplacing and mitochondrial dysfunction in amyotrophic lateral sclerosis pathogenesis. Front. Cell. Neurosci. 9:336. doi: 10.3389/fncel.2015.00336

Tan, W., Naniche, N., Bogush, A., Pedrini, S., Trotti, D., and Pasinelli, P. (2013). Small peptides against the mutant SOD1/Bcl-2 toxic mitochondrial complex restore mitochondrial function and cell viability in mutant SOD1-mediated ALS. J. Neurosci. 33, 11588-11598. doi: 10.1523/JNEUROSCI.5385-12.2013

Tosatto, L., Andrighetti, A. O., Plotegher, N., Antonini, V., Tessari, I., Ricci, L., et al. (2012). Alpha-synuclein pore forming activity upon membrane association. Biochim. Biophys. Acta 1818, 2876-2883. doi: 10.1016/j.bbamem.2012.07.007

Um, J. W., Kaufman, A. C., Kostylev, M., Heiss, J. K., Stagi, M., Takahashi, H., et al. (2013). Metabotropic glutamate receptor 5 is a coreceptor for Alzheimer a $\beta$ oligomer bound to cellular prion protein. Neuron 79, 887-902. doi: 10.1016/ j.neuron.2013.06.036 
Um, J. W., Nygaard, H. B., Heiss, J. K., Kostylev, M. A., Stagi, M., Vortmeyer, A., et al. (2012). Alzheimer amyloid- $\beta$ oligomer bound to postsynaptic prion protein activates Fyn to impair neurons. Nat. Neurosci. 15, 1227-1235. doi: 10.1038/nn.3178

Umeda, T., Tomiyama, T., Sakama, N., Tanaka, S., Lambert, M. P., Klein, W. L., et al. (2011). Intraneuronal amyloid $\beta$ oligomers cause cell death via endoplasmic reticulum stress, endosomal/lysosomal leakage, and mitochondrial dysfunction in vivo. J. Neurosci. Res. 89, 1031-1042. doi: 10.1002/ jnr. 22640

Valente, E. M., Abou-Sleiman, P. M., Caputo, V., Muqit, M. M. K., Harvey, K., Gispert, S., et al. (2004). Hereditary early-onset parkinson's disease caused by mutations in PINK1. Science 304, 1158-1160. doi: 10.1126/science.1096284

Vande Velde, C., Miller, T. M., Cashman, N. R., and Cleveland, D. W. (2008). Selective association of misfolded ALS-linked mutant SOD1 with the cytoplasmic face of mitochondria. Proc. Natl. Acad. Sci. 105, 4022-4027. doi: $10.1073 /$ pnas.0712209105

Vivoli Vega, M., Cascella, R., Chen, S. W., Fusco, G., De Simone, A., Dobson, C. M., et al. (2019). The toxicity of misfolded protein oligomers is independent of their secondary structure. ACS Chem. Biol. 14, 1593-1600. doi: 10.1021/acschembio. $9 \mathrm{~b} 00324$

Walsh, D. M., Klyubin, I., Fadeeva, J. V., Cullen, W. K., Anwyl, R., Wolfe, M. S., et al. (2002). Naturally secreted oligomers of amyloid $\beta$ protein potently inhibit hippocampal long-term potentiation in vivo. Nature 416, 535-539. doi: 10.1038/ $416535 \mathrm{a}$

Wang, H.-Y., Li, W., Benedetti, N. J., and Lee, D. H. S. (2003). $\alpha 7$ Nicotinic acetylcholine receptors mediate $\beta$-amyloid peptide-induced tau protein phosphorylation. J. Biol. Chem. 278, 31547-31553. doi: 10.1074/jbc. M212532200

Ward Sarah, M., Himmelstein Diana, S., Lancia Jody, K., and Binder Lester, I. (2012). Tau oligomers and tau toxicity in neurodegenerative disease. Biochem. Soc. Transac. 40, 667-671. doi: 10.1042/bst20120134

Westermark, G. T., Krogvold, L., Dahl-Jørgensen, K., and Ludvigsson, J. (2017). Islet amyloid in recent-onset type 1 diabetes-the DiViD study. Upsala J. Med. Sci. 122, 201-203. doi: 10.1080/03009734.2017.1359219
Westermark, P., Andersson, A., and Westermark, G. T. (2011). Islet amyloid polypeptide, islet amyloid, and diabetes mellitus. Physiol. Rev. 91, 795-826. doi: 10.1152/physrev.00042.2009

Wiedemann, F. R., Manfredi, G., Mawrin, C., Beal, M. F., and Schon, E. A. (2002). Mitochondrial DNA and respiratory chain function in spinal cords of ALS patients. J. Neurochem. 80, 616-625. doi: 10.1046/j.0022-3042.2001.00 731.x

Winner, B., Jappelli, R., Maji, S. K., Desplats, P. A., Boyer, L., Aigner, S., et al. (2011). In vivo demonstration that $\alpha$-synuclein oligomers are toxic. Proc. Natl. Acad. Sci. 108, 4194-4199. doi: 10.1073/pnas.110097 6108

Wong Su, S., Chieng, A., Parres-Gold, J., Chang, M., and Wang, Y. (2018). Realtime determination of aggregated alpha-synuclein induced membrane disruption at neuroblastoma cells using scanning ion conductance microscopy. Faraday Discussions 210, 131-143. doi: 10.1039/C8FD0 0059J

Yamamoto, N., Matsubara, T., Sato, T., and Yanagisawa, K. (2008). Age-dependent high-density clustering of GM1 ganglioside at presynaptic neuritic terminals promotes amyloid $\beta$-protein fibrillogenesis. Biochim. Biophys. Acta 1778, $2717-$ 2726. doi: 10.1016/j.bbamem.2008.07.028

Zhang, Y., Zhao, Y., Zhang, L., Yu, W., Wang, Y., and Chang, W. (2019). Cellular prion protein as a receptor of toxic amyloid- $\beta 42$ oligomers is important for Alzheimer's disease. Front. Cell. Neurosci. 13:339. doi: 10.3389/fncel.2019.00339

Conflict of Interest: The authors declare that the research was conducted in the absence of any commercial or financial relationships that could be construed as a potential conflict of interest.

Copyright (c) 2021 Gonzalez-Garcia, Fusco and De Simone. This is an open-access article distributed under the terms of the Creative Commons Attribution License (CC BY). The use, distribution or reproduction in other forums is permitted, provided the original author(s) and the copyright owner(s) are credited and that the original publication in this journal is cited, in accordance with accepted academic practice. No use, distribution or reproduction is permitted which does not comply with these terms. 